\title{
An Incident Management System for Debt Collection in Virtual Banking
}

\author{
Sareh Saberi* \\ Department of Computer Engineering, Science and \\ Research Branch, \\ Islamic Azad University, \\ Tehran, Iran
}

\author{
Seyyed Mohsen Hashemi \\ Department of Computer Engineering, Science and \\ Research Branch, \\ Islamic Azad University, \\ Tehran, Iran
}

\begin{abstract}
An astonishing peak volume of bad loans in most countries, including Iran, is one of the latest manifestations of deep disorders which inhibited banking system from performing its main duty to promote development plans over a long period. Main mission of banking system is to link savers and those economic actors who need financial facilities. Banks, as intermediaries, receive interest from the second group and pay interest to the first group. During the last 10 years, millions of people have been controlling their financial lives online in the developed markets. Counters of access to electronic money and electronic wallet have increased currently. Bad loans increase as more facilities are provided for customers. Therefore, a mechanism is required for debt collection without any need for physical bank and improvement of this process using incident management system.
\end{abstract}

Keywords-virtual banking; debt collection; incident
management

\section{INTRODUCTION}

Currently, information technology is known as an integral part of all industries and areas of activity. Few areas of industrial, commercial and service activities can be found which do not require IT to achieve their goals. Banking industry is one of the main economic activities in which IT is widely used as a key element. In current banks, IT is blood in vessels of the bank; all banking activities are through this context. Part of financial resources of banks and financial and credit institutions, which are granted to recipients of facilities, is in the form of bad loans. This group of customers discourages re-granting of financing facilities and ideal banking services to customers. Credit risk has been always a threat to banking activity. The risk of non-repayment of loans taken from banks is always considered as bad loans in financial headlines. Thus, banks have been always concerned with observation of bad loans to granted facilities. According to the studies conducted, if this ratio reaches $20 \%$, it will be a risk for the bank. Using data analysis, this study develops a system which can improve debt collection and return these financial resources to the banking industry $[1,2,3]$.

Information Technology Infrastructure Library (ITIL) is a systematic approach to quality of IT services. Details of the most important processes of an IT organization such as task list, instructions and responsibilities provides a basis to accommodate needs of various organizations. Development and dissemination of this approach provided useful guidelines in many fields which resulted in growth and development of IT organizations. In simple terms, ITIL can be considered as a standard in the field of IT, while the reality is that ITIL is not a standard $[4,5]$.

\section{DEFINITION OF INCIDENTS}

Modified ITIL terminology defines incident as any event that is not part of a standard operation and cause service interruptions or reduced quality of the service. The purpose of ITIL is to achieve normal operation in the shortest possible time with minimal effect on trade or user by spending an affordable cost. Incidents may occur due to certain or uncertain reasons and they are recorded eventually to control problem management in Known Error Database. Incidents result from underlying IT problems and errors. The cause of incidents may be known and clear and may not need any investment in terms of time of cost for identifying. These incidents may lead to an application for maintenance, a physical presence at the site, or a change request to remove error. Where an incident is raised to be seriously and vigorously pursued or several events similar to an incident are observed, a problem could be recorded as a solution to all cases in the system. A problem may not be recorded until several similar problems are reported. Management of a problem is different from management process of an incident and it is done by different employees; for this reason, it is controlled by problem management process. When a problem is identified, the problem is recognized as a problem. Once the cause of an incident is detected, it becomes a detected error. Finally, a change request may be created for changing the system or eliminating the detected error. This process is covered by a change management process. Note that, request for an additional service is not recognized as an incident; instead, it is called a change request $[4,6]$.

\section{INCIDENT MANAGEMENT BASED ON ITIL}

Purpose of incident management is to restore normal servicing operations at minimum time possible and to minimize effect of hazards and inconsistencies in commercial operations. Normal service operation here is defined as a service operation within limits of the service level agreements. In other words, incident management is a part of the IT service management. Its primary goal is to restore normal servicing operations at minimum time possible and to minimize its negative effects such as lack of servicing in commercial operations. Incident refers to any event which is not routine 
component of a service and may stop the service or reduce quality of the service. Process management monitors processing, allocates resources to different layers of this process, insures the updated database, and uses these tools efficiently; other responsibilities of management include planning and reporting [7].

\section{COMPARISON OF SERVICE DESK APPLICATIONS}

To evaluate features of different service desks in order to identify characteristics of incident management, these applications are compared in terms of three following companies which annually report experiences of customers with available applications.

\section{A. IDC MarketScape}

- Leader: ServiceNow, BMC Software.

- Major Player: CherWell Software, CA Technologies, IBM, HP.

- Contenders: LANDESK, ZOHO

- Participants

\section{B. Gartner}

- Leader: ServiceNow, BMC Software

- Challengers: CherWell Software, CA Technologies

- Visionares: Landesk, Axios Systems

- Niche Players: FronRange, IBM, EasyVista, HP, ManageEngin, SysAid Technologies, TOPdesk, Hernbill

\section{Forrester}

- Leader: SysAid Technologies, CherWell Software, ServiceNow.

- Strong Perfomers: EasyVista, FronRange, Zendesk, TOPdesk, Vivantlo.

- Contenders: Landesk, Axios Systems

- Risky Bets

By comparing features, it is concluded that a full service desk should have following characteristics: Mobile, WebBased, Alert/Escalation, Asset Management, Asset life Cycle Management, Automated, Assignment/Routing, Contract Management, Work Flow, Customer DataBase, Customer Self Service Ticket Management, Knowledge Base, Reporting, Incident Management, Problem Management, Change Management, Configuration Management, CRM, SMS, Social Media Integration Surveys \& Feedback, Live Chat, Email Integration, Community Forums, Telephony $[8,9,10]$.

\section{VIRTUAL BANKING}

In a virtual bank, customers and users are the same and both use banking services vie internet. Important efforts have been made for virtual banking worldwide. Statistics released by the International Monetary Fund indicate that virtual banking is mostly used in Austria, Finland, Korea, Singapore, Spain, Sweden and Switzerland where more than $75 \%$ of banks deliver internet services. In America, those banks providing internet services possess more than $90 \%$ of assets of banking system. Although most customers have accounts in banks providing e-banking services, only $4 \%$ of them are customers of these banks. There are few virtual banks in the world; by 2001, there were only nine virtual banks with independent charter and almost 20 virtual banks with special trademark in America and two virtual banks in Asia and several virtual banks in European Union [11, 12, 13].

\section{DEBT COLLECTION}

According to the latest information and formal and informal interviews, there is 800 thousand billion tomans cash operating in Iran, of which 150 thousand billion tomans as bad loans has not been returned to the banks. Portfolio of bad loans shows that about $60 \%$ of these loans are doubtful headings. Statistical analysis suggests that more than half of the portfolio of bad loans is in disposal of few people (not more than 100 people). Therefore, the crisis in bank liquidity cycle is an uncommon problem which needs to be addressed. By definition, bad loans are divided into two groups of current and non-current loans. Current loans refer to those loans that two months have passed their due date. These loans are traced in banks as current heading. Non-current loans include past due, overdue and doubtful headings. Time is involved in definition of these headings. By definition, those loans that more than two months and less than six months have passed their due date are past due loans. Overdue loans are those loans that more than six months and less than eighteen months have passed their due date. Doubtful loans are those loans that more than eighteen months have passed their due date $[1,3]$.

\section{METHODS}

Using UML concepts, Activity Diagrams are depicted for traditional debt collection, electronic debt collection and the suggested system by using features of incident management system and results of comparison of the best service desks as well as features of virtual banking to suggest the virtual debt collection process.

\section{TRADITIONAL DEBT COLLECTION}

Three categories of information are required for filing:

- Information of loans including the type of contract signed by the customer at the time of receiving loans

- Type of collaterals and guarantees received from the customer at the time of receiving loans

- Full information of the debtor including ID, addresses, work, email address and contact information

Once this information is imported to the debt collection system, it is analyzed and separated. Then, the file is referred to a debt collection expert who sends a text message to cellphone of the debtor recorded in the file. The text message is determined by consulting with legal department. In a stepwise fashion, the text message gradually becomes a warning. As an important principle in debt collection, leverages are intensified gradually on the debtor to repay debt (Figure 1) [14,15]. 


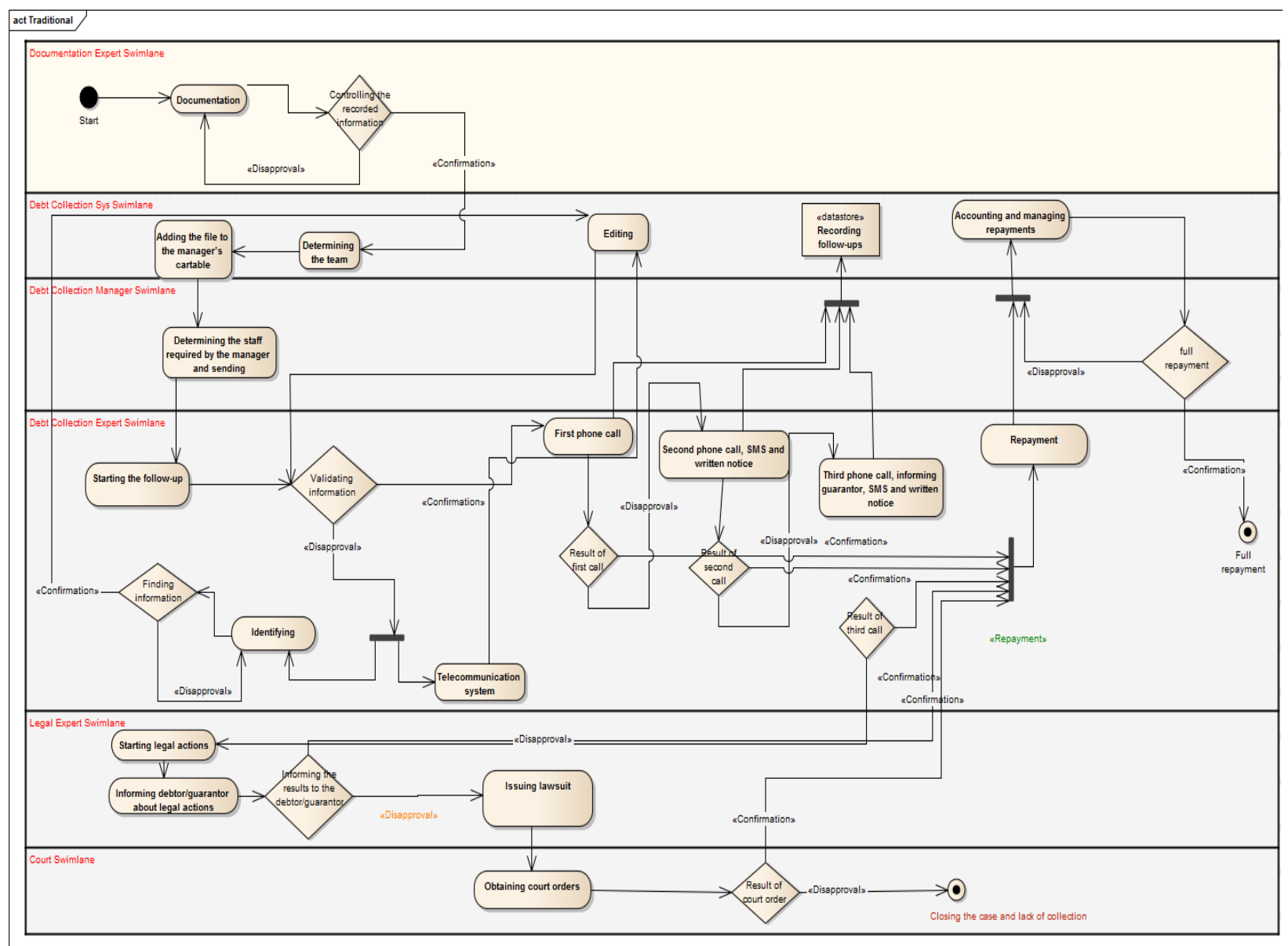

Fig. 1. Traditional Debt Collection Activity Diagram

\section{FIRST IMPROVEMENT USING VIRTUAL B ANKING FEATURES, ELECTRONIC DEBT COLLECTION SYSTEM}

The process starts with visiting the website and filling the application forms to obtain loans. The qualified applicant is asked to upload the scanned documents. Then, the uploaded documents are evaluated in terms of accuracy and adequacy. Validation starts by reviewing the documents and available information. Validation eventually leads to credit rating, based on which bank credit committee decides whether to grant the loan. All records of BadPay saved in this database are considered as input for validation. By analyzing validation information, the customer will be informed if the loan is not to be granted. Otherwise, the customer is informed after the loan is deposited in customer account. The customer is informed of amount and due date of the first installment. Once the loan is deposited, the system starts accounting and payment management. If the installments are not paid in the determined due date, debt collection experts make the first follow-up contact (Figure 2). 


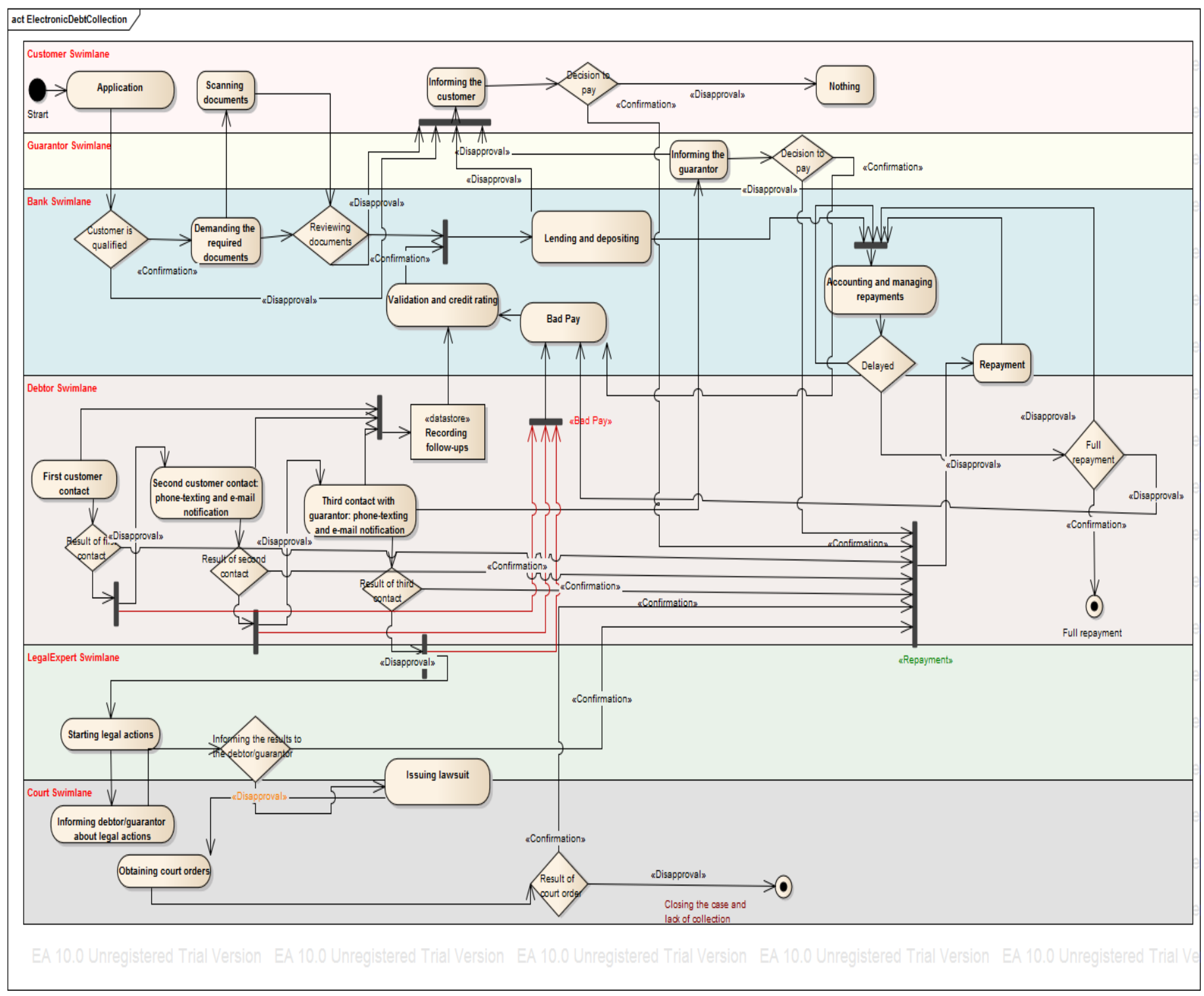

Fig. 2. Electronic Debt Collection Activity Diagram

\section{The Suggested Methodology}

\section{A. Incident Management System for Debt Collection in Virtual Banking}

The operation starts with visiting the website and filling the application form. The application form contains information on type of loan, rate of interest, ID and claimed collaterals. The system makes decisions automatically and online by considering customer choices, information and documents by connecting to central databases such as Document Registration Organization to investigate property collaterals announced, Civil Registration Organization to investigate claimed information and Telecommunication Organization to investigate contact numbers and addresses as well as BadPay output which is explained below. The customer is rated through BadPay outputs and payment behavior of previous loans using Knowledge Base feature of Service Desk. The output is compiled in a Black List of people who are not qualified and do not have collaterals. Once the information is received, the system makes decision on the granting the loan. If the loan is allowed, the requested amount will be directly deposited in account of the applicant. The customer is informed of deposition, repayment period, due date of the first installments, and amount of installment. Moreover, the system informs the customer upon depositing the loan. If the applicant is not qualified, the system will inform the applicant vie email and SMS. Systemic operation of accounting and repayment management starts once the loan is deposited. In fact, on time repayment is monitored in the system. At each stage of due date, lack of repayment is recorded as Badpay in this system. All Badpay records are analyzed in a database called as customer payment behaviors, containing a history of customer actions and reactions in repayment; for example, the database shows repayments after stages of follow-up. Based on these records, decisions are made on granting loans and follow-up operations of debt collection. One requirement of loan is guarantor(s). Informing system is applicable for the guarantor in the next stages. If the customer does not repay upon the first 
due date, accounting system and repayment management and the follow-up debt collection systematically start to work using repayment behavior of customer. The first follow-up is through phone call using IVR which informs legal consequences of non-compliance with repayment obligations. The system extends the deadline for repayment and studies customer behavior in the extended period. If the customer does not repay at the deadline, it will be recorded as a Badpay and the system starts the next stage to continue follow-up. Next follow-ups involve phone calls, SMS and email. In case of repayment at any follow-up stages, it is recorded in the accounting system and repayment management; otherwise, the second Badpay is recorded for the customer. At the third stage of follow-up, the system informs both customer and guarantor about legal consequences of the guarantee. If the guarantor does not respond, the system records Badpay for the guarantor. If the third follow-up does not lead to repayment, the system will refer the file to the legal follow-up department. From the beginning, the customer and the guarantor are informed of legal actions. The deadline is extended to one week; in case of non-repayment, the file is referred to the judicial authorities for follow-up by calculating interest, fines and debt to the date. This stage involves issuing of a lawsuit by sending information to online system of judicial authorities and court's decision and ultimately issuing the definitive execution to force the customer or the guarantor to repay the debt. All repayment procedures ultimately lead to complete repayment of the debt. In each stage of follow-up, the debtor may attempt to pay off debts, which is done in repayment process. In addition, payment management and accounting system constantly monitors the customer's account. According to central bank laws, lending becomes difficult and even impossible to individuals and guarantors in the banking network. By linking to judicial systems, this can lead to automatic issuing of travel bans. Some of banking services may be discontinued later. For example, Shetab network services may be disrupted or money transfer may not be available (Figure 3).

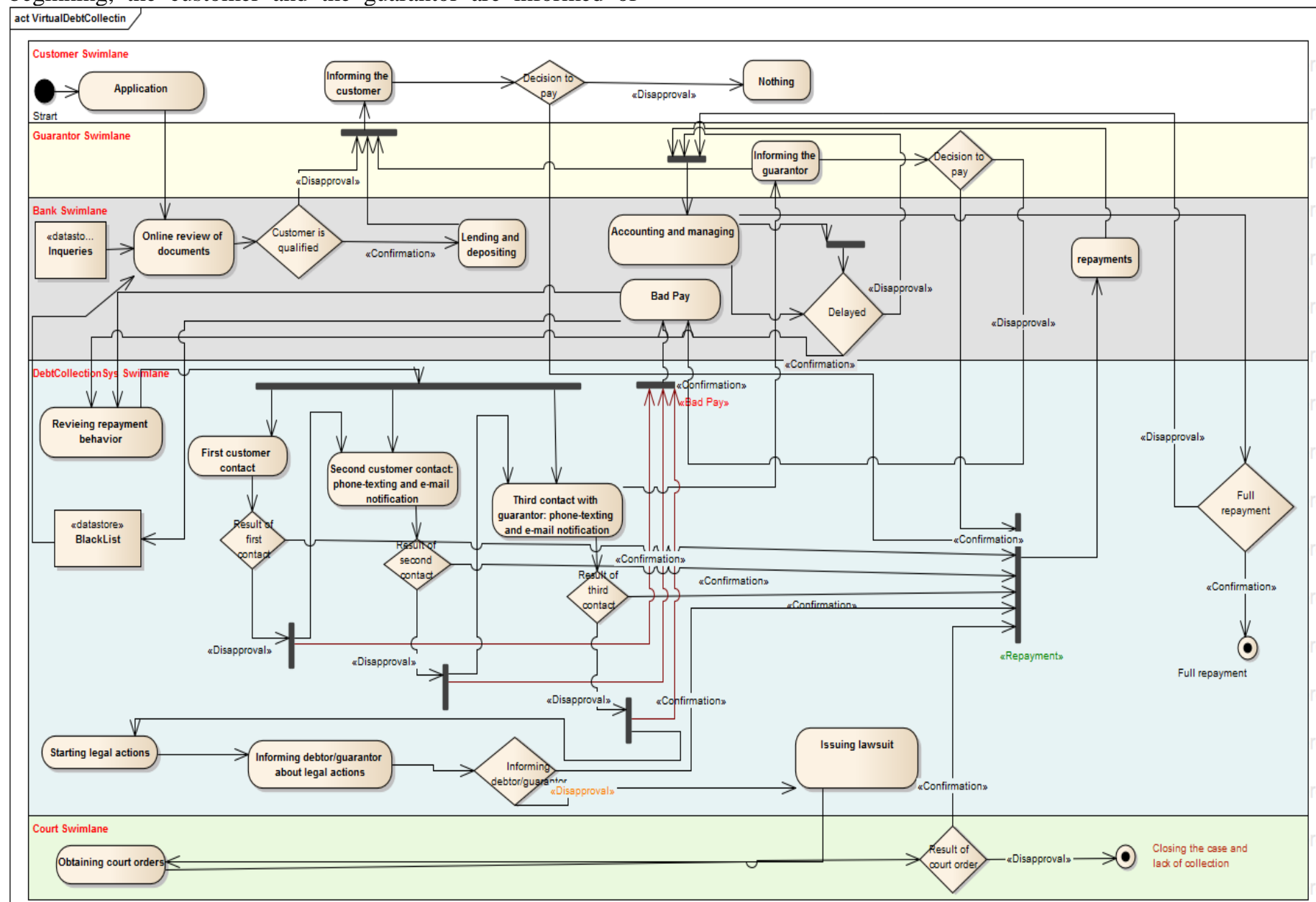

Fig. 3. Incident Management System for Debt Collection in Virtual Banking Activity Diagram 


\section{System Evaluation}

\section{A. Measurement of Effectiveness}

An inclusive study is required to evaluate systemic improvements done. The figure below determines logical chain of this study:

\section{1) Information}

- Easily received and processed information

- Easily validated information

2) Customer satisfaction

- Customer self-validation

- Easy lending

- Transparent informing

- Access to sufficient information at any time

3) Debt collection process

- Reduced costs of ineffective follow-ups
- Improved repayment behavior for satisfaction

- Completed database of non-creditworthy customers and prevention of next bad loans

\section{MEasurement OF CUSTOMER Satisfaction by Kano MODEL}

Results of the survey of 100 customers analyzed by Kano model show that customers are most concerned with attractive factors followed by must-be and basic factors considered in virtual banking. The lowest score given by respondents to the questions F16 and F23 results from their lack of understanding of the menus; this can be attributed to the fact that respondents had no experience with the real website and only considered the simulated scenario. In conclusion, the results show that customer satisfaction with attractive, must-be and basic factors increases overall satisfaction of users; positive responses are expected from repayment behavior of customers (Table 1 and 2 and Figure 4) [16, 17].

TABLE I. CUSTOMER SURVEY

\begin{tabular}{|c|c|c|c|c|c|c|c|c|}
\hline & Question & Class & 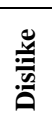 & 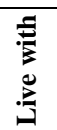 & $\begin{array}{l}\overline{\tilde{E}} \\
\bar{E} \\
\bar{E}\end{array}$ & 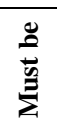 & 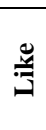 & है \\
\hline F1 & $\begin{array}{l}\text { Meeting customer information needs in relation to types of lending } \\
\text { contracts }\end{array}$ & Attractive & 1 & 0 & 2 & 12 & 35 & 230 \\
\hline $\mathbf{F 2}$ & Satisfaction with informing process & Attractive & 1 & 2 & 11 & 25 & 11 & 193 \\
\hline F3 & Providing sufficient information through alarms in the customer profile & Attractive & 3 & 2 & 15 & 22 & 8 & 180 \\
\hline F4 & Usage of promotions and forgiveness of crimes and satisfaction & Attractive & 0 & 0 & 23 & 10 & 17 & 194 \\
\hline F5 & $\begin{array}{l}\text { Customer opinion about reduced cost of commuting due to the new } \\
\text { method }\end{array}$ & Attractive & 1 & 0 & 16 & 19 & 14 & 195 \\
\hline F6 & Supporting views and reforms & Attractive & 1 & 3 & 12 & 22 & 12 & 191 \\
\hline F7 & New information & Attractive & 1 & 5 & 19 & 16 & 9 & 177 \\
\hline F8 & How lack of validation impairs customer intention & Attractive & 1 & 1 & 3 & 32 & 13 & 205 \\
\hline F9 & $\begin{array}{l}\text { Lack of information about debt collection process has an effect on } \\
\text { customer satisfaction }\end{array}$ & Attractive & 2 & 2 & 1 & 29 & 16 & 205 \\
\hline F10 & $\begin{array}{l}\text { Lack of promotions and motivations (informing, forgiveness, commuting } \\
\text { cost) }\end{array}$ & Attractive & 0 & 1 & 1 & 38 & 10 & 207 \\
\hline F11 & Easy communication and access to customer service & Basic & 2 & 2 & 5 & 26 & 15 & 200 \\
\hline F12 & Easily met customer expectations from menus & Basic & 1 & 1 & 9 & 28 & 11 & 197 \\
\hline F13 & Ability to search information & Basic & 1 & 3 & 4 & 36 & 6 & 193 \\
\hline F14 & Accurate presentation & Basic & 1 & 2 & 3 & 38 & 6 & 196 \\
\hline F15 & Help tables and content menus & Basic & 0 & 2 & 18 & 24 & 6 & 184 \\
\hline F16 & What do you think if the menus are removed? & Basic & 3 & 1 & 3 & 11 & 11 & 113 \\
\hline F17 & Do you agree with removal of the search feature? & Basic & 0 & 1 & 3 & 21 & 25 & 220 \\
\hline F18 & How would lack of help tables be effective on easy access? & Basic & 4 & 4 & 3 & 22 & 17 & 194 \\
\hline F19 & $\begin{array}{l}\text { How do customers with bad loan evaluate the new debt collection } \\
\text { system? }\end{array}$ & Indifferent & 0 & 1 & 3 & 34 & 12 & 207 \\
\hline F20 & Suitable and sufficient resolution of webpages & Indifferent & 2 & 1 & 6 & 40 & 1 & 187 \\
\hline F21 & Ability to monitor the status of any pending case online & Questionable & 0 & 0 & 8 & 38 & 4 & 196 \\
\hline F22 & Overall satisfaction with virtual debt collection services & Questionable & 0 & 2 & 23 & 15 & 10 & 183 \\
\hline $\mathbf{F 2 3}$ & Ability to show user's position on the website & Questionable & 10 & 14 & 16 & 8 & 2 & 128 \\
\hline F24 & Logical structure of information provided & Questionable & 0 & 2 & 10 & 32 & 6 & 192 \\
\hline F25 & Information is available on the site until needed & Questionable & 3 & 5 & 9 & 28 & 5 & 177 \\
\hline F26 & Statement of information along with their details & Questionable & 2 & 3 & 7 & 23 & 15 & 196 \\
\hline F27 & Satisfaction with responsiveness and support & Reverse & 0 & 0 & 12 & 37 & 1 & 189 \\
\hline F28 & Satisfaction with continuous collection and follow-up services & Reverse & 0 & 0 & 11 & 16 & 23 & 212 \\
\hline F29 & $\begin{array}{l}\text { Ability to monitor credit rating and systemic self-evaluation and customer } \\
\text { satisfaction }\end{array}$ & Must-be & 2 & 1 & 7 & 20 & 20 & 205 \\
\hline F30 & $\begin{array}{l}\text { Online monitoring of bad loans and installments and customer } \\
\text { satisfaction }\end{array}$ & Must-be & 1 & 1 & 14 & 18 & 16 & 197 \\
\hline F31 & Ensuring that the data imported by the user is stored and maintained & Must-be & 0 & 0 & 5 & 42 & 3 & 198 \\
\hline
\end{tabular}




\begin{tabular}{|c|c|c|c|c|c|c|c|c|}
\hline F32 & To display load time and system response & Must-be & 0 & 1 & 11 & 22 & 16 & 203 \\
\hline F33 & User help & Must-be & 0 & 8 & 16 & 20 & 6 & 174 \\
\hline F34 & Updated information & Must-be & 3 & 5 & 10 & 21 & 11 & 182 \\
\hline F35 & How important is the outdated information? & Must-be & 1 & 3 & 10 & 35 & 1 & 182 \\
\hline F36 & $\begin{array}{l}\text { How effective is the lack of load display and system response on } \\
\text { satisfaction? }\end{array}$ & Must-be & 3 & 2 & 4 & 36 & 5 & 188 \\
\hline F37 & What do you think if data security is not guaranteed? & Must-be & 0 & 1 & 3 & 39 & 7 & 202 \\
\hline
\end{tabular}

TABLE II. CLASSIFICATION OF QUESTIONS BASED ON KANO

\begin{tabular}{|l|l|l|l|l|l|}
\hline & Dislike & Live with & Neutral & Must be & Like \\
\hline Attractive & 0.02 & 0.03 & 0.21 & 0.45 & 0.29 \\
\hline Basic & 0.03 & 0.04 & 0.12 & 0.52 & 0.24 \\
\hline Indifferent & 0.02 & 0.02 & 0.09 & 0.74 & 0.13 \\
\hline Questionable & 0.05 & 0.09 & 0.24 & 0.48 & 0.14 \\
\hline Reverse & 0 & 0 & 0.23 & 0.53 & 0.24 \\
\hline Must-be & 0.02 & 0.05 & 0.18 & 0.56 & 0.19 \\
\hline
\end{tabular}

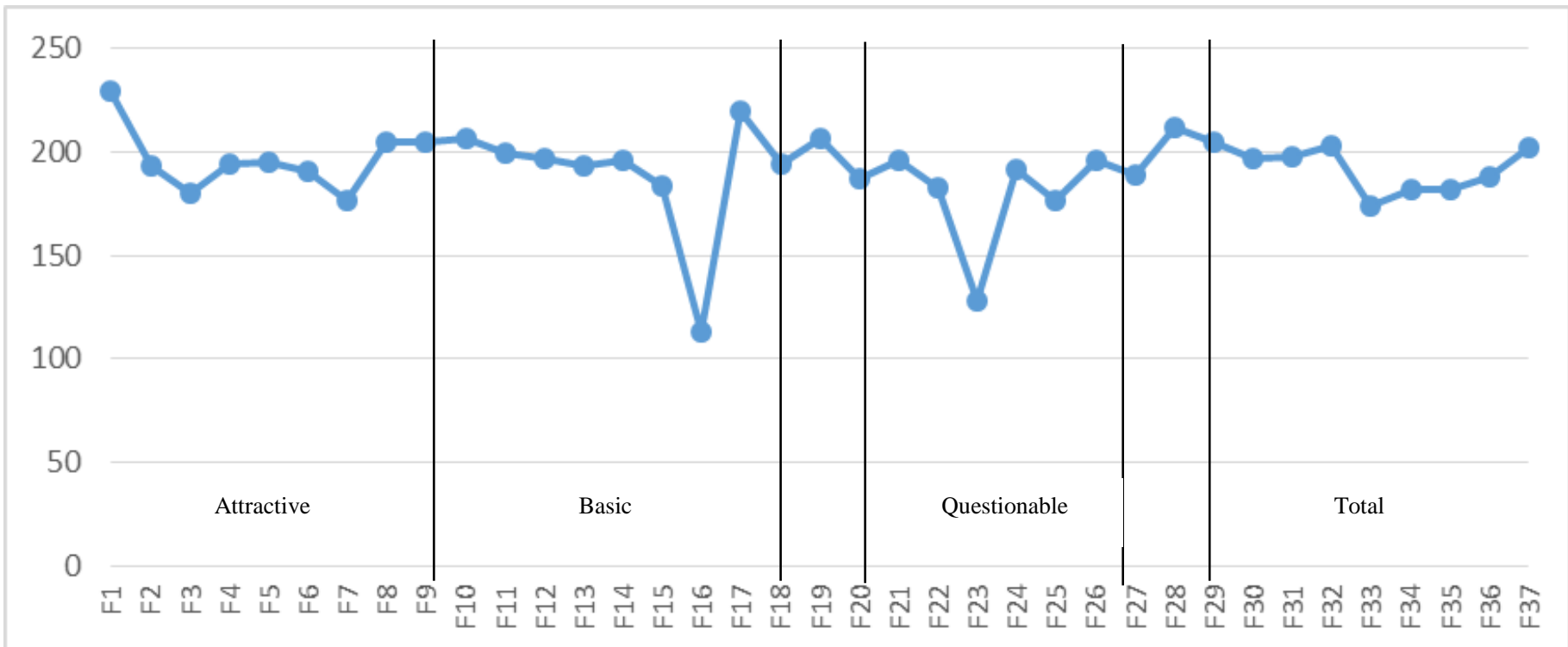

Fig. 4. Frequency of questions based on Kano

\section{INDICATORS OF EFFECTIVENESS}

By determining chain strategies used to create value added, an indicator is defined for each goal; then, methods are developed for calculating these indicators. Thus, summarized steps of this evaluation are determined for effectiveness, path control and tactics to achieve organizational goals. For this purpose, it is essential to recognize scientific and practical concepts for determining the indicators. Using balanced scorecard (BSC), performance evaluation indicators are divided into three categories [18]:

- Key result indicators (KRIs)

- Performance indicators (PIs)

- Key performance indicators (KPIs)

Indicators of debt collection are extracted from activities of a debt collection company as shown in Table 3.

\section{CONCLUSION}

Given that debt collection is based on customer data, precision and accuracy of information is important for this mission. In traditional debt collection, information is recorded manually as input to the debt collection system; due to the size of information, human error is probable and may disrupt the debt collection process. Moreover, traditional debt collection lacks a database which can convert raw customer data using BadPay records to analytical information based on knowledge management. Moreover, the traditional system cannot monitor customer behaviors in debt collection, on time repayment or follow-up contacts. Consequently, this information gap causes latent costs. Repeated follow-ups extend the debt collection. Losses of delays and follow-ups cannot be estimated easily. Some of the costs such as written notice can be calculated; moreover, costs of each type of follow-ups can be estimated. However, latent cost is the tip of the iceberg. In addition to primary validation, repayment behavior of the customer is evaluated at the time of debt collection. The traditional system lacks this feature. In fact, customer validation prevents bad loans. Written notice requires a large amount of paper, human resources and time; moreover, the customer may not receive the notice. There may be conflicts in contracts and the relevant staff may not notice the conflicts. Traditional system suffers a considerable amount of human error. There are advantages and disadvantages in the electronic system. However, the electronic system has improvements compared to the traditional system. 
Advantages of the electronic system include online application for the loan and informing process at different stages. Although the electronic system has been improved, it suffers shortcomings such as time-ineffectiveness and additional process. This system does not allow online validation simultaneously with application. It is time consuming to validate the information claimed by the applicant, because it requires inquiries from the relevant organizations. One advantage of the electronic system is that validation starts with access to the information. However, disadvantage of the system is that the applicant is required to upload the scanned documents and the bank needs to send these documents to the relevant organizations for validation; this prolongs the process. Compared to traditional and electronic systems, an inclusive database and integrated information is an advantage of virtual system. Based on incident management model, virtual banking enables a relatively smart system. In the virtual system, the customer fills the application form containing primary information, type of loans and rate of interest; by connecting to a systematic database, the system extracts and analyzes records of the applicant. To save the costs, the applicant can login to the validation system to know his credit rate and predict agreement or disagreement with his application. The database containing BadPay, BlackList records and the systems linked to DataSharing departments accelerate lending process. This system analyzes raw data and customer reactions to loans and repayments and determines a history of previous loans. For debt collection, the system finds a suitable method based on behaviors, actions and reactions and makes decisions intelligently. The system suffers no human error in recording the information and the steps are taken rapidly. In virtual debt collection, the system receives personal information, addresses and guarantors and validates them through databases of relevant organizations such as Document Registration Organization, Civil Registration Organization, and Telecommunication Organization. Using central bank database, the customers with BadPay records are alarmed when applying for the loan and validating online. There is no need for prolonged legal process. The files are referred to the court online. In this study, virtual debt collection system was implemented by using features of incident management and service desk. A central database was developed by using mobile base and web base to integrate and validate information using features of virtual banking. Alert and email used to inform debtors save time and cost. Customer database and customer self-service enables customers to validate themselves before applying. Using a history of all banking activities, customers can validate themselves and improve their conditions if they are not qualified. Using knowledge management, previous activities and repayments of the customers can be monitored and used for validation and determination of the warning suitable for the customers. Table 4 and Table 5 summarize advantages and disadvantages of traditional, electronic and virtual banking systems. 
TABLE III. EFFECTIVENESS INDICATORS OF DEBT COLLECTION IN VIRTUAL BANKING SYSTEM

\begin{tabular}{|c|c|c|c|}
\hline $\begin{array}{l}\text { Type of } \\
\text { Indicator }\end{array}$ & Formula & Effectiveness & Indicator \\
\hline KPI & $\begin{array}{l}\text { Number of complaints (questions with average to weak rating) / total } \\
\text { surveys (all questions responded) } \times 100\end{array}$ & Customer satisfaction & Customer satisfaction \\
\hline
\end{tabular}

Correct information flow and improved quality of customer service increases customer satisfaction in surveys and indirectly influences repayment behavior of customers.

\begin{tabular}{|l|l|l|l}
\hline PI & Total number of follow ups / total number of debtors $\times 100$ & Debt collection \\
\hline
\end{tabular}

Through a direct relationship between transparency and facilitated flow of information and increased customer satisfaction, total number of follow-ups directly decreases. Given that the number of files or debtors is constant, the follow-up rate decreases. In other words, lower follow-up is required for collection of bad loans compared to the traditional debt collection system.
KPI
Number of depositing files / total number of bad loans $\times 100$
Debt collection
Depositing file ratio

Given that a number of bad loans remain unpaid until they are referred to a legal entity, an important indicator must always monitor success rate of pre-legal and post-legal measures. This shows a logical relationship with customer behavior. Even decision on immediate referral to the legal department can avoid excessive time and energy spent on some files by controlling costs. Therefore, regular monitoring of the number of depositing files is important for the bank. Many debtors ted to extend or repay through re-installment. Thus, depositing files involve those who have not yet repay completely and had multiple repayments.
KRI
Collection rate (RLS) / Total amount of bad loans $\times 100$
Debt collection
Collection to portfolio ratio

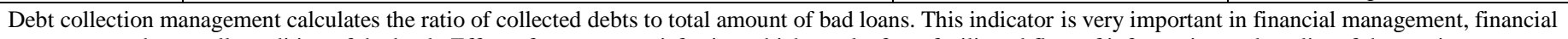
statements and generally auditing of the bank. Effect of customer satisfaction which results from facilitated flow of information and quality of the services provided manifests itself in this indicator.
PI
Number of paid loans / total number of bad loans $\times 100$
Debt collection
Paid loan ratio

Debt collection management requires customers to accept the terms of contracts including rate of interest and penalty and pay their debts completely. Thus, debt collection system requires an indicator for determining completely paid loans. This indicator is successful when numerator and denominator approach to 1 . Apart from the amount of debt, this indicator directly refers to the paid loans.

\begin{tabular}{|l|l|l|l}
\hline KRI & $\begin{array}{l}\text { Administrative fee of debt collection (phone, SMS, IVR, etc.) / total } \\
\text { amount of collected debts } \times 100\end{array}$ & Debt collection/information & Cost to collection ratio \\
\hline
\end{tabular}

One of the indicators which are directly related to facilitated flow of information and customer satisfaction is the reduced number of follow-ups and consequently reduced costs of these follow-ups. The lower the numerator, the higher the collected debts and profitability will be.

\begin{tabular}{|l|l|l|l|}
\hline PI & $\begin{array}{l}\text { (Cost of paper + phone calls + SMS + IVR) + cost of staff salary / total } \\
\text { organizational expenses }\end{array}$ & Debt collection/information & Cost ratio \\
\hline
\end{tabular}

This ratio shows the share of costs to total administrative expenses. It is in fact the bottleneck of organizational expenses and involves those costs which are directly involved in debt collection process.

\begin{tabular}{|c|c|c|c|}
\hline PI & $\begin{array}{l}\text { The number of referrals to legal department / total number of bad loans } \\
\times 100\end{array}$ & Customer satisfaction & $\begin{array}{l}\text { Number of referrals to legal } \\
\text { department }\end{array}$ \\
\hline PI & $\begin{array}{l}\text { Amount of files referred to legal department / total number of bad loans } \\
\times 100\end{array}$ & Customer satisfaction & $\begin{array}{l}\text { Amount of files referred to legal } \\
\text { department }\end{array}$ \\
\hline
\end{tabular}

These two indicators show those customer behaviors referred to legal department for banking contracts or amount of debts. It also indicates decision of the organization to save the time and reduce costs by referring the files to the legal department immediately. On the other hand, this indicator shows effectiveness of pre-legal processes and customer satisfaction indirectly. From a win-win perspective, this indicator reduces costs of legal actions for both customers and the bank. The bank tends to refer less files to the legal department; for this, the bank needs to inform the customer and explain costs of legal actions to the customer.

TABLE IV. COMPARISON OF DEBT COLLECTION SYSTEMS

\begin{tabular}{|c|c|c|c|c|c|c|c|c|c|c|c|c|c|}
\hline & 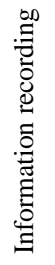 & 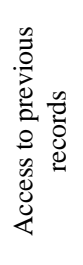 & 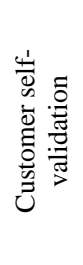 & 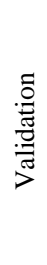 & $\sum_{\sim}^{\infty}$ & $\stackrel{\alpha}{\geq}$ & 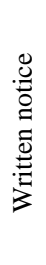 & 胥 & 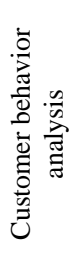 & 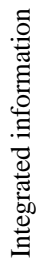 & 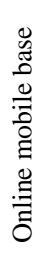 & 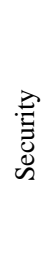 & 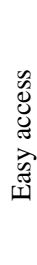 \\
\hline Traditional system & $\sqrt{ }$ & $x$ & $\times$ & $x$ & $\sqrt{ }$ & $\sqrt{ }$ & $\sqrt{ }$ & $x$ & $x$ & $x$ & $x$ & $x$ & $\times$ \\
\hline Electronic system & $x$ & $\sqrt{ }$ & $x$ & $\sqrt{ }$ & $\sqrt{ }$ & $\sqrt{ }$ & $\bar{x}$ & $\sqrt{ }$ & $x$ & $\sqrt{ }$ & $\sqrt{ }$ & $\sqrt{ }$ & $\sqrt{ }$ \\
\hline Virtual system & $\bar{x}$ & $\sqrt{ }$ & $\sqrt{ }$ & $\sqrt{ }$ & $\sqrt{\sqrt{ }}$ & $\sqrt{ }$ & $\bar{x}$ & $\sqrt{\sqrt{ }}$ & $\sqrt{ }$ & $\sqrt{ }$ & $\sqrt{ }$ & $\sqrt{ }$ & $\sqrt{ }$ \\
\hline
\end{tabular}


TABLE V. ADVANTAgES OF ViRTUAL DEBt COLleCtion

\begin{tabular}{|l|l|}
\hline Advantages of virtual debt collection \\
\hline Higher profitability & Reduced time of collection \\
\hline Reduced bad loans & Inexpensive services \\
\hline No physical money & Continuous smart validation and follow-up \\
\hline Reduced possibility of misuse & Easy to use \\
\hline Fast transactions & Higher quality \\
\hline Record of activities & Accuracy of information \\
\hline Increased customer satisfaction & Inclusiveness \\
\hline Full-time services & \\
\hline
\end{tabular}

\section{REFERENCES}

[1] Central Bank of the Islamic Republic of Iran. debt collection guideline for credit institutions. tehran: central bank, central bank publication, Iran, vol. 1, 2008

[2] M. SABETI, H. FARSIJANI, M. KASAEI, M. HAMIDIZADEH, Cumhuriyet University Faculty of Science,Science Journal (CSJ), vol. 36, No. 6, 2015.

[3] Central Bank of the Islamic Republic of Iran, non-current debt collection guideline for credit institutions. tehran: central bank, 2015.

[4] P. Bernard. Foundations of ITIL® 2011 Edition.2012

[5] https://en.wikipedia.org/wiki/ITIL

[6] The Office of the Government Chief Information Officer"” INFORMATION SECURITY INCIDENT HANDLING GUIDELINES”, The Government of the Hong Kong Special Administrative Region, vol. 1, 2012.

[7] CityBank, "Debt Collections Standards in India Citibank Code for collection of dues \& Repossession of Security" "Version Eleven، vol. 1, April 2014.

[8] C. Gliedman, The Forrester Wave ${ }^{\mathrm{TM}}$ : Service Desk Management Tools, vol. 4, 2006.
[9] J. M. Brooks, and G. Jarod. "Magic quadrant for IT service support management tools." vol. 7,2012 .

[10] IDC MarketScape: Worldwide Service Desk Management Software Vendor Analysis. vol. 1, 2014.

[11] H. Moeinzade, difference in advantages and effects of virtual banking development. virtual banking, vol. 1, 2012.

[12] K. Naboure, comparison of virtual banking services of top 10 virtual banks . virtual banking, vol. 1, 2012.

[13] M. Hatami, M. electronic service development in smart city. virtual banking, vol. 1, 2012.

[14] B. Kercher, Debt Collection Harassment in Australia (Part 2). Monash UL Rev., vol. 5, pp. 204, 1978.

[15] V. Fedaseyeu, \& R. M. Hunt, The economics of debt collection: enforcement of consumer credit contracts, vol. 1, 2015.

[16] E. Sauerwein , F. Bailom, K. Matzler, Hans H. Hinterhuber, International Working Seminar on Production Economics,Innsbruck/Igls/Austria, vol. 1, pp. 313 -327, 1996.

[17] http://www.parsmodir.com/thesis/kano.php.

[18] R. S. Kaplan, D. P. Norton “" The Balanced Scorecard:Translating Strategy into Action.Boston" "Harvard Business School Press, vol. 1, 2004. 